\title{
Práticas de formação colaborativa de professores/as de inglês: representações de uma experiência no Pibid
}

\section{English Language Teacher Collaborative Practices: Representations of an Experience within Pibid}

Elaine Mateus*

Universidade Estadual de Londrina

Londrina - Paraná / Brasil

RESUMO: Este estudo tem o objetivo de analisar representações de práticas de formação colaborativa de professores/as de inglês, pela perspectiva de licenciandos/ as envolvidos/as no Programa Institucional de Bolsas de Iniciação à Docência (Pibid) Letras-Inglês-Universidade Estadual de Londrina (Capes 01/2011). Os dados, gerados por meio de um questionário em escala Likert e de um grupo focal, foram analisados com base na análise de discurso crítica, com destaque às categorias de metáfora e de avaliação. Os resultados indicam tensōes entre representações que giram ao redor das metáforas troca de ideias e troca de figurinhas, cada uma representando aspectos em termos de regras de participação e de papéis sociais (in)desejáveis. $\mathrm{O}$ estudo aponta para implicações que as posições híbridas trazem para as práticas de formação de professores/as no interior do Pibid.

PALAVRAS-CHAVE: colaboração; formação de professores/as; Pibid; representação; análise de discurso crítica.

ABSTRACT: This study aims at analyzing representations of English language teacher collaborative practices, from the perspective of student teachers involved in Teaching Initiation Scholarship Program (Pibid, Capes 01/2011). The data, generated through a Likert scale questionnaire and a focus group, were analyzed based on critical discourse analysis, highlighting the categories of metaphor and evaluation. The results indicate the tensions between representations that revolve around metaphors of "exchange of ideas" and "exchange of stickers", each representing aspects of rules in terms of participation and (un)desirable social roles. The study indicates some implications that hybrid positions bring to the practices of teacher education within Pibid.

KEYWORDS: collaboration; teacher education; Pibid; representation; critical discourse analysis.

*mateus@uel.br 


\section{Introdução}

Nos últimos anos um número crescente de estudos tem abordado aprendizagem como prática social (LAVE, 1988; LAVE; WENGER, 1991; ROGOFF, 1995) em comunidades (por exemplo, Wenger [1998] e Rogoff, Turkanis e Bartlett [2001]). O pressuposto de que aprendizagem é um processo dinâmico de identidades que se transformam no fluxo da ação, do pensamento e do diálogo lança luz sobre práticas colaborativas como mediadoras do devir humano.

$\mathrm{Na}$ área da formação de professores/as, tanto no Brasil quanto em outros países, há igualmente estudiosos/as que compartilham o sentido de que aprendizagem se forja em processos colaborativos de práxis sociodiscursivaeducacional (ROTH; TOBIN, 2001; 2002; 2004; MATEUS, 2005; 2007; 2009; MAGALHÃES; FIDALGO, 2008; 2010; LIBERALI; MAGALHÃES, 2009; MAGALHÃES, 2009a; 2009b; MATEUS; QUEVEDO-CAMARGO; GIMENEZ, 2009; PICONI; MATEUS, 2011). Em comum, boa parcela dessas pesquisas se dedica a compreender os processos de ensino-aprendizagem como parte de "uma reflexão teórica sobre os aspectos semióticos da transformação social” (FAIRCLOUGH, 2011, p. 119).

No âmbito das políticas de investimento na formação de professores/ as, propostas de rompimento das barreiras que separam a universidade da escola têm ocupado espaço central. Assim como na literatura acadêmica, os conceitos de colaboração, de comunidade e de parceria têm prevalecido nos documentos recentes produzidos pelas secretarias de educação. Nesse contexto encontra-se, entre outros, o Programa Institucional de Bolsas de Iniciação à Docência (Pibid), foco de interesse deste trabalho, que se insere no Projeto Práticas Colaborativas de (Transform)ação de Professores/as: Um Olhar sob as Lentes da Análise de Discurso Crítica. ${ }^{1}$

O estudo parte do pressuposto de que, se por um lado, o fomento a redes de trabalho e a parcerias constitui formas de governança e de gerenciamento da vida social (FAIRCLOUGH, 2003; MATEUS, no prelo), por outro, os modos como essas iniciativas são compreendidas e postas em ação ligam-se às atitudes, experiências sociais e ideologias prévias dos indivíduos, compartilhadas com outros membros do grupo (VAN DIJK,

\footnotetext{
${ }^{1}$ Projeto aprovado pelo CEP/Conep, processo CAAE: 14990613.8.0000.5231, parecer no 287.529.
} 
2010). Práticas dessa natureza se dão, portanto, mediadas, tanto por resistências e constrangimentos preexistentes, quanto por possibilidades de transformação. Assim, esse estudo justifica-se pela necessidade de se compreender a dinâmica dessas forças antagônicas e, ao mesmo tempo, propulsoras de transformação, pela voz daqueles/as que vivenciam experiências de prática colaborativa. Com isso em mente, são analisadas representações sobre práticas de formação colaborativa, por licenciandos/as no curso de Letras-Inglês, da Universidade Estadual de Londrina (UEL), envolvidos no subprojeto Pibid-Letras-Inglês, contemplado pelo Edital Capes 001/2011.

O texto está organizado em quatro seçóes: na primeira, apresento estudos que tratam da colaboração, em especial, na formação de professores/ as; na segunda, discuto o Pibid como espaço potencialmente capaz de gerar práticas de formação colaborativa de professores/as, com destaque às ações propostas pelo curso de licenciatura Letras-Inglês da UEL para o período de julho de 2011 a junho de 2013; na terceira, descrevo a pesquisa e sua metodologia de geração e de análise dos dados e, na quarta, analiso dados provenientes de um questionário e de um grupo focal realizado com licenciandos/as naquele contexto. Ao final, teço considerações sobre os resultados e aponto algumas implicaçôes do estudo.

\section{Colaboração e formação de professores/as}

Nos últimos vinte anos, conceitos como colaboração, parceria e comunidade tornaram-se lugar comum nos meios de comunicação de massa, nos espaços acadêmicos e educacionais, no mundo dos negócios e da política. E "quando um termo como colaboração se torna popular", afirmam JohnSteiner, Weber e Minnis (1998, p. 774), "ele precisa ser definido". Assim, a presente discussão mapeia algumas definições de colaboração, com foco na área de formação docente, e tece consideraçóes sobre o conceito de parceria em suas dimensões epistemológicas e pedagógicas.

Engeström (1994), ao tratar da colaboração entre professores/as envolvidos/as em planejamento de currículo, define o que ele chama de pensamento colaborativo como "integrado à atividade coletiva prática e, assim, essencialmente como interativo, dialógico, e argumentativo" (p. 43). No quadro da teoria da atividade sócio-histórico-cultural em que se encontra, o autor aborda colaboração em sua perspectiva ontológica, partindo do princípio de que a multiplicidade de vozes e pontos de vista constitui a natureza própria da atividade e do desenvolvimento humano. 
Também inseridos na perspectiva sócio-histórica, Matusov e Hayes (2002) definem aprendizagem como a produção de uma comunidade de educadores-aprendizes na qual professores/as e alunos/as têm a oportunidade de participar plenamente de práticas que sejam suficientemente significativas, criativas e capazes de oferecer sentidos de pertença. Essa é uma concepção que decorre de estudos anteriores em que colaboração se define como

atividade conjunta na qual participantes se engajam mutualmente na definição e desenvolvimento de objetivos no interior da própria atividade, resolvendo problemas, coordenando esforços, respeitandose mutuamente como os mais valiosos agentes de suas próprias ações e tentando integrar suas atividades com outros aspectos de suas vidas. (MATUSOV; WHITE, 1996, p. 11)

Na mesma direção, Roth e Tobin $(2001 ; 2002 ; 2004)$ exploram os sentidos de aprendizagem como participação em comunidades de prática educacional a partir do conceito de ensino colaborativo como prática que "permite a emersão de desafios mais significativos e, deste modo, abre possibilidades para se aprender com o outro não somente de modo explícito, mas igualmente e ainda mais importante, de modo tácito" (ROTH; TOBIN, 2002, p. 121). Por sua natureza e formas de organização, o ensino colaborativo potencialmente produz as bases comuns a partir das quais participantes da ação refletem sobre os eventos em sessōes de diálogo cogerativo, cujo propósito é promover aprendizagem por meio de oportunidades de analisar questóes significativas sob os diversos pontos de vista dos envolvidos no mesmo evento.

Clark et al. (1996) têm foco em pesquisas colaborativas e, com base em narrativas de professores/as e de pesquisadores/as, definem colaboração como diálogo e como "partilha e mutualidade não em termos de fazer o mesmo trabalho de pesquisa mas, ao contrário, em termos de compreender o trabalho uns dos outros" (CLARK et al., 1996, p. 196, grifos do original). Para JohnSteiner, Weber e Minnis (1998, p. 774), o foco exclusivo no diálogo acaba por mitigar a "complementaridade de habilidades, esforços e papéis nas relações de confiança como alternativa para a falta de equidade e para o poder desigual em algumas colaborações ou para todos fazendo trabalhos idênticos".

Embora John-Steiner (2000) não trate de colaboração na perspectiva da formaçāo de professores/as, seu estudo tem sido referência para discutir diferentes padrōes de colaboração. Para ela, trabalhos cooperativos não podem ser confundidos com trabalhos colaborativos. Aqueles caracterizam-se por contribuiçōes específicas para as tarefas também específicas, ao passo que estes caracterizam-se pela equidade 
de papéis e responsabilidades entre participantes envolvidos/as em tarefas comuns. Há, contudo, variações de intensidade, de duração e de objetivos nos grupos envolvidos em trabalho colaborativo, o que permite distinguir quatro padrōes de colaboração: distribuida, complementar, familiar e integrativa. Aquela que se aproxima das definições anteriores que vimos aqui é a colaboração integrativa, na qual participantes compartilham o desejo de transformação da prática em que estão envolvidos/as, a disponibilidade para realização comum, o diálogo e os esforços para a superação de conflitos e de diferenças, com vistas à promoção do outro. Nesse modelo, são essenciais o interesse comum apaixonado, a escuta cuidadosa, o envolvimento emocional, os propósitos compartilhados, a apropriação mútua, a responsabilidade individual pelo bem comum e os processos contínuos de resolução de conflitos e tensões.

Também Furlong et al. (2000) identificaram três modelos de parceria universidade-escola no contexto da Inglaterra: a parceria complementar; a parceria colaborativa e a parceria conduzida pela Instituição de Ensino Superior (IES). A parceria colaborativa, mesmo não sendo a mais comumente vivenciada nas práticas investigadas, é aquela mais constantemente definida como ideal. Segundo os autores, esse modelo caracteriza-se pelo compromisso com um programa educacional que permita aos/às licenciandos/as lidar com diferentes formas de conhecimento advindos da escola, da universidade e de outros contextos de relevância. Em parcerias colaborativas, os/as participantes criam oportunidades para trabalhar juntos/as as etapas de planejamento, execução e discussão crítica das práticas pedagógicas, valorizando e reconhecendo como legítimas as diferenças.

Em todos os casos, Furlong et al. (2000) argumentam que parceria não é um mero conceito organizacional, mas uma prática que incorpora importantes dimensões epistemológicas e pedagógicas. Epistemologicamente, as parcerias assumem que escolas e universidades são instituiçôes diferentes que oferecem, cada uma, um conjunto diferente de saberes e de práticas. Pedagogicamente, as parcerias impõem arranjos próprios que impactam não somente naquilo que os/as participantes aprendem, mas, igualmente, nos modos como aprendem.

No entanto, ao contrário de Furlong et al. (2000), argumento a seguir que essas dimensões, antes de instanciadas em eventos específicos, são somente potenciais presentes nas práticas sociais de formação de professores/as. O domínio potencial refere-se "ao que quer que exista, seja natural ou social, independentemente de ser um objeto empírico para nós e de termos uma compreensão adequada de sua natureza" (SAYER, 2000, p. 11). Assim, o Pibid como conjunto 
de regras e normas legalistas enunciadas em documentos do governo federal operacionaliza formas de (inter)agir, formas de ser e formas de organizar a educaçāo em determinadas direções. Contudo, sua realização depende de atores sociais, situados em práticas específicas, ocupando lugares específicos, lidando com um conjunto complexo de contingências preexistentes que constrangem ao mesmo tempo em que potencializam suas ações.

\section{O Pibid como possibilidade de novas práticas e posições sociais}

O Pibid é uma iniciativa do Ministério de Cultura e Educação (MEC), executado no âmbito da Coordenação de Aperfeiçoamento de Pessoal de Nível Superior (Capes), ambos órgãos do governo federal, cujas políticas de fomento caminhavam em vias paralelas até 2007, quando da publicação da Lei n. 11.502, em que foram modificadas as competências e a estrutura organizacional da Capes a fim de autorizar a concessão de bolsas a participantes de programas de formação inicial e contínua de professores/as da educação básica. O Pibid configura-se, portanto, como expressão da parceria entre essas instituições, sendo esse um aspecto já bastante significativo de suas características geminais, e caracteriza-se como peça essencial na engrenagem que impulsiona o plano de governo lançado em 2007 para operacionalizar "uma política de Estado, desenhada na gestão anterior e formalizada no Plano Nacional de Educação (PNE) 2001-2011, aprovado como Lei n. $10.172 \mathrm{em} 9$ de janeiro de 2001. ${ }^{2}$

Em linhas gerais, o Pibid surge, explicitamente, em resposta à necessidade de fortalecimento das licenciaturas, em um momento em que a crise no magistério e os baixos indicativos educacionais evidenciam colapso e, implicitamente, à critica de que os cursos de licenciatura formam inadequadamente professores/as para atuarem na educação básica - o que explica, em parte, o envolvimento da Capes conferindo ao trabalho nas licenciaturas o "selo de qualidade" que imprime nos cursos de pós-graduação. Embora o primeiro edital do Pibid tenha sido lançado em 2007 para as áreas de Física, Química, Biologia e Matemática, somente em nível de Ensino Médio, em 2009, com a divulgação do Relatório Preliminar da Fundação Carlos Chagas sobre a atratividade na carreira docente (GAFFURI, 2012) e a publicação do Decreto n. 6.755, em que se institui a Política Nacional de Formação de Profissionais do Magistério da Educação Básica e se disciplina a

${ }^{2}$ Para uma discussão crítica sobre essa conjuntura, ver Mateus (no prelo). 
atuação da Capes no fomento a programas de formação inicial e contínua, o Pibid estende-se para todas as licenciaturas da educação básica.

Conforme Decreto n. 7.219, de 24 de junho de 2010, são objetivos do Pibid:

I - incentivar a formação de docentes em nível superior para a educação básica;

II - contribuir para a valorização do magistério;

III - elevar a qualidade da formação inicial de professores nos cursos de licenciatura, promovendo a integração entre educação superior e educação básica;

IV - inserir os licenciandos no cotidiano de escolas da rede pública de educação, proporcionando-lhes oportunidades de criação e participação em experiências metodológicas, tecnológicas e práticas docentes de caráter inovador e interdisciplinar que busquem a superação de problemas identificados no processo de ensino-aprendizagem;

$\mathrm{V}$ - incentivar escolas públicas de educação básica, mobilizando seus professores como co-formadores dos futuros docentes e tornando-as protagonistas nos processos de formação inicial para o magistério; e

VI - contribuir para a articulação entre teoria e prática necessárias à formação dos docentes, elevando a qualidade das ações acadêmicas nos cursos de licenciatura.

O que se mostra de maior relevância para o objetivo desse texto é a ênfase concedida ao trabalho que visa aproximar universidade e escola no processo de formação de professores/as, como se deixa ver nas escolhas de "integração entre educação superior e educação básica", "inserir os licenciandos no cotidiano de escolas", "professores como co-formadores dos futuros docentes", "articulação entre teoria e prática". Mesmo cientes de que não é por seu caráter normativo que se dá, ipso facto, a colaboração como possibilidade de ressignificação de lugares sociais e de protagonismo docente, esses propósitos potencializam as oportunidades de criação de práticas e de posições híbridas.

Defino hibridismos como um sistema posição-prática (BHASKAR, 1998) que projeta rearticular outras práticas e posicionamentos híbridas sob circunstâncias específicas "a fim de criar graus próprios de estabilidade e durabilidade para articulacões específicas, bem como criar potenciais próprios para articular práticas de formas novas" (CHOULIARAKI; FAIRCLOUGH, 1999, p. 13). Nisso residem os potenciais epistemológicos e pedagógicos do Pibid, conforme apontado por Furlong et al. (2000). 
Epistemologicamente, o Pibid como conjunto de normas em aspecto legalista potencializa as possibilidades de que diferentes conhecimentos sejam rearticulados tanto a partir daquilo que está consolidado como conhecimento historicamente acumulado quanto a partir daquilo que se vivencia no cotidiano da sala de aula. Pedagogicamente, o Programa potencializa as possibilidades de que diferentes formas de organização curricular superem as dificuldades presentes na estrutura das IES e das escolas de educação básica.

Assim, o Pibid pode ser definido como esse espaço potencial de transição entre uma formação que historicamente tem sido representada como "teórica" e o trabalho na escola. No entanto, como um espaço ainda novo, as posições sociais dos atores nele envolvidos não estão objetivamente dadas. Como vimos, o documento projeta "licenciandos inseridos no cotidiano da escola" e "professores da educação básica mobilizados como co-formadores" sem, contudo, dizer de que modos esses (dis)posicionamentos se realizarão. É somente nos eventos sociais que se realizam no cotidiano daqueles que dão vida a esse espaço que essas (dis)posições vão sendo subjetivamente preenchidas.

No caso específico do subprojeto de Letras-Inglês da UEL, contemplado pelo Edital Capes 001/2011, de 15 de dezembro de 2010, e do qual participam os/as licenciandos/as neste estudo, as principais metas são: (a) permitir a licenciandos/as do curso de Letras-Inglês, tomar contato, observar e refletir coletivamente sobre as características do ensino de inglês em escolas públicas; (b) desenvolver projetos em grupos envolvendo licenciandos/as das séries iniciais e finais do curso de Letras, ${ }^{3}$ de modo a documentar etnograficamente as práticas escolares com relação ao ensino de inglês; (c) propor inovação metodológica e monitorar seus resultados; (d) contribuir para a renovação curricular da própria licenciatura à medida que os/as discentes poderão trazer subsídios de sua vivência na escola pública para o currículo de formação de professores/as na universidade; (e) permitir ao/a professor/a colaborador/a envolver-se mais diretamente na formação de novos profissionais e conhecer mais profundamente seus/suas alunos/as e a escola onde atua.

Nessa recontextualização, destaco os aspectos que remetem à colaboração enunciados em "refletir coletivamente" e "desenvolver projetos em grupo".

\footnotetext{
${ }^{3}$ As séries iniciais compreendem o 10 ano e 20 ano do curso e as séries finais correspondem ao 30 e $4^{\circ}$ ano, sendo estas as séries em que o estágio curricular obrigatório acontece.
} 


\section{A pesquisa}

O objetivo desta discussão é compreender as representaçōes de práticas de formação colaborativa de professores/as de inglês, conforme texturizadas por licenciandos/as do segundo, terceiro e quarto ano do curso de Letras-Inglês, que vivenciaram experiências dessa natureza no subprojeto Pibid/UEL/LetrasInglês, ao longo de 2011. Para tanto, debruço-me sobre a análise de textos gerados por meio de um grupo focal e de um questionário em escala Likert.

O questionário em escala Likert foi aplicado a dez alunos/as, em outubro de 2011. O material continha 29 perguntas, cuja escala variava de 1 a 6 , sendo 1 "discordo plenamente" e 6 "concordo plenamente". O questionário é uma adaptação de Collaboration Q-Score, desenvolvido por Vera Jonh-Steiner e Kathryn Miller (ver Jonh-Steiner [2000]) com o propósito de levantar informaçōes sobre vários aspectos de trabalhos colaborativos. A adaptação das questôes foi inicialmente pensada para servir de motivação para alunos na disciplina Formação Colaborativa de Professores de Línguas: Questôes Teóricas e Metodológicas, ministrada no Programa de Pós-Graduação e Estudos da Linguagem. O objetivo do questionário nesse trabalho de pesquisa foi o de buscar elementos e pistas que permitissem melhor delimitar os temas e focos do grupo focal. As análises serviram também de apoio para triangulação dos dados e interpretação dos resultados aqui apresentados.

Os grupos focais são caracterizados como método de pesquisa qualitativa, "desenhado para explorar um conjunto específico de questōes, tais como as visões e experiências das pessoas" (KRZYZANOWSKI, 2008, p. 162). O propósito residiu não somente na possibilidade de discutir questôes relativas às experiências no Pibid, como também representaçóes dos/as participantes sobre essas mesmas experiências. A sessão que analiso foi realizada em novembro de 2011 e teve como objetivo explorar os sentidos individuais e coletivos da prática de formação colaborativa. O moderador foi um aluno do segundo ano do curso de Letras, envolvido em projeto de iniciação científica, e as temáticas estavam assim orientadas: o que é formação colaborativa; como se organizam práticas de formação colaborativa de professores/as; o que diferencia essas práticas de outros modelos de formação; que aprendizagens foram possíveis àqueles que experimentaram práticas colaborativas; que contribuições modelos colaborativos podem trazer para a formação de professores/as. Participaram desse grupo focal sete dos/as alunos/as que responderam ao questionário, além da professora formadora. À exceção do nome do moderador, os demais nomes serão aqui alterados para garantir anonimato às/aos demais participantes. 
A análise dos dados apoia-se na análise de discurso crítica (doravante $\mathrm{ADC}$ ) (CHOULIARAKI; FAIRCLOUGH, 1999; FAIRCLOUGH, 2003) como base teórico-metodológica que orienta a concepção de linguagem como prática social, materializada linguisticamente nos textos. Falar da linguagem nessa perspectiva significa compreender que, ao produzirmos textos específicos, produzimos vida social, relaçôes sociais e identidades sociais. Para a ADC, o texto tem ao mesmo tempo efeitos que reproduzem e transformam as estruturas sociais, por meio de informações delas provindas (RESENDE, 2009).

Neste estudo qualitativo, de natureza interpretativista, concentro a análise nas categorias de metáforas e de avaliação, que serão discutidas no decorrer da análise.

\section{Formação colaborativa de professores/as e posições híbridas}

Disse anteriormente que esta pesquisa filia-se, por um lado, a teorias sociais de aprendizagem e desenvolvimento humano e, por outro, a teorias críticas de linguagem. $\mathrm{Na}$ revisão dos estudos que tratam de colaboração, especialmente em práticas de formação de professores/as, concedi destaque àqueles que concebem aprendizagem como um processo (social e não mental/ individual) que se dá em contextos de práticas (sociais) por meio de interaçôes (sociais) que se realizam, principalmente, pela linguagem. Nessa discussão dos dados, me aproximo do arcabouço teórico-metodológico da ADC de Fairclough e compartilho o pressuposto de que a "linguagem é uma parte irredutível da vida social" (FAIRCLOUGH, 2003, p. 2), por meio da qual significados são (re)criados.

Nessa perspectiva, Fairclough discute três tipos principais de significados nos textos: acional, representacional e identificacional. Esses significados correspondem, respectivamente, aos modos de agir (gêneros), de representar (discursos) e de identificar (estilos). Ação, representação e identificação são significados que mantêm entre si relação dialética, sendo distintos somente para fins analíticos. Isso porque as representaçōes de aspectos do mundo social são também instanciadas nos modos de (inter)agir e inculcadas nas identidades dos agentes sociais, do mesmo modo que as açôes e as identidades são representadas no discurso.

Isso justifica a escolha pelas metáforas e pela avaliação como categorias analíticas deste estudo. Embora sejam frequentemente empregadas para tratar do significado identificacional nos textos (FAIRCLOUGH, 2003; RESENDE, 2009), a perspectiva dialética em que "significados identificacionais em textos 
podem ser vistos como pressupondo significados representacionais" (FAIRCLOUGH, 2003, p. 160) me permitiu partir da análise dessas categorias para investigar as representações de licenciandos/as sobre práticas colaborativas de formação, em um curso de licenciatura. Assim, discuto representaçóes de práticas colaborativas com base nas metáforas e, concomitantemente, trato daquilo que é desejável e indesejável pela avaliação dos/as licenciandos/as sobre a formação colaborativa. Nos exemplos, os números à esquerda indicam os turnos na sequência do grupo focal e o uso de "[...]" sinaliza omissão de enunciados, feita com base no critério de apresentar exemplos concisos e suficientes para ilustrar a análise pretendida.

( 1 )

11 Isabela: [...] através de formação colaborativa, assim... ela... ela se reflete tanto na vida do estagiário, quanto na vida dos professores da escola, quanto na da Aline [professora formadora] [...] então, pra mim, formação colaborativa seria isso... essa troca de ideias.

[...]

13 Fernando: [...] acho que é todo mundo se ajudando em todas as escalas possíveis, desde o grau aluno-aluno, aluno com professores... é::: o grupo de trabalho da escola, os professores... eu acho que é todo mundo se ajudando e trocando figurinha.

\section{[...]}

17 Fernando: Eu acho que antes de tudo é um time. Tem que ter compromisso prévio de cada um no grupo pra poder a coisa funcionar... se cada um fizer a sua parte, tudo caminha naturalmente... aí, se começar a falhar, ai começa a não dar...

[...]

20 Isabela: Bom, eu acho que eu entendi a sua pergunta [referindo-se ao mediador do grupo focal] um pouco diferente. Pelo menos aqui assim existe de certa forma uma hierarquia, que seria isso aqui, a professora formadora [...] parte muitas vezes dela assim a iniciativa... é assim muitas vezes é como se ela fosse o nosso motor... mas nós também temos essa participação direta, então existe essa divisão assim... existe essa organização [...]

O uso de metáforas "sugere filiação a uma maneira particular de representar aspectos do mundo e de identificá-los” (RESENDE, 2009, p. 138). A metáfora de "troca de ideias" é introduzida por Isabela para responder à pergunta "o que você entende por formação colaborativa?", feita no início dos trabalhos pelo mediador do grupo focal. Essa "troca de ideias" se conclui a partir 
da metáfora do reflexo ("[a formação colaborativa] se reflete tanto na vida do estagiário...”). O reflexo remete a "tudo aquilo que cria o duplo, que supóe duas cenas, duas articulações, passagem para uma outra dimensão, que, sendo outra, entretanto, reflete a primeira, nunca se esgotando como pura repetiça-o" (LOPES, 2012, p. 109). Dizer que a formação colaborativa "se reflete na vida" dos participantes permite a Isabela representar a experiência em seu vínculo duplo: por um lado, articulada ao mundo da teoria e, por outro, ao mundo da vida que se vive e, por assim ser, ligada à historicidade viva e experimentada pelos participantes. Essas duas dimensões são colocadas novamente em cena ao final do grupo focal, como analisarei mais adiante (exemplo 5).

Ainda no turno 11, Isabela escolhe indicar explicitamente em que vidas essa formação se reflete e o faz elencando, primeiramente, a vida "do estagiário", depois a vida "dos professores da escola" e, por último, a vida da professora da universidade. Essas metáforas de "troca de ideias" e de "reflexo" na vida dos diferentes atores sociais envolvidos no Pibid levam a supor tanto a construção de sentidos de colaboração marcados pelo apagamento da hierarquia quanto pela impossibilidade de "dizer" essa hierarquia. Voltarei a isso em breve.

Na sequência do turno 11, Fernando parece fazer um movimento de interdiscursividade, se apropriando da metáfora de "troca". No entanto, ao escolher representar a formação colaborativa como troca de figurinhas - que, em nossa cultura, remete tanto à brincadeira de criança quanto a embates, disputas e conquistas entre quem participa - Fernando dá início a outros sentidos dessa formação. Trocar figurinhas envolve colocar à disposiçãao do outro aquilo que sobra, aquilo que é repetido, aquilo que já não me interessa e esperar que o outro entregue, em troca, aquilo que ainda não tenho. Também indica, no entanto, que as experiências podem ser complementares, e que todos/as têm algo a contribuir.

Isso se vê novamente mais adiante (turno 17), quando a colaboração é também representada por outra metáfora: time. Nessa fala, time está associado, por um lado, à "ajuda mútua" ("todo mundo se ajudando em todas as escalas"; "todo mundo se ajudando e trocando figurinha") e, por outro, à 'ação individual' ("tem que ter compromisso prévio de cada um"; "se cada um fizer a sua parte”). Quando somada à metáfora da troca de figurinhas, leva a construir sentidos de formação colaborativa como a soma de indivíduos; um trabalho em grupo no qual predominam as contribuiçōes fragmentadas em que cada um traz uma parte para compor o todo da tarefa. Na definição de Furlong $e t$ al. (2000), uma parceria complementar. 
O mapeamento metafórico revela ainda a formação colaborativa em termos de máquina (funcionar; falhar; motor). É Fernando quem introduz a metáfora (turno 17), indicando como mecanismo de acionamento o compromisso que cada um deve trazer consigo para o trabalho no grupo ("tem que ter compromisso prévio de cada um no grupo pra coisa funcionar"). $\mathrm{O}$ compromisso colocado como obrigatoriedade por meio de modalidade deôntica alta ("tem que ter compromisso prévio") marca também aquilo que Fernando entende como desejável para essa formação colaborativa. Para ele, tanto o compromisso quanto a ação são individuais e o funcionamento da máquina depende de cada um fazendo sua parte, assim como em um time em que cada jogador tem sua posição bem definida.

Em seguida, Isabela adere à metáfora (turno 20), mas dá a ela outros contornos. A ignição é muitas vezes (e não sempre) a iniciativa da professora formadora, mas o funcionamento da máquina depende de todos. $\mathrm{O}$ uso da expressão é como se ela fosse nosso motor indica que é preciso haver uma força motriz, mas que essa força está distribuída pela "participação direta" de todos no grupo. Ao mesmo tempo, a metáfora da professora como motor dilui a participação e a responsabilidade dos/as demais e sinaliza centralização.

A avaliação emite sentidos sobre o que é desejável e indesejável, "o que é bom e o que é ruim" (FAIRCLOUGH, 2003, p. 172). Essa análise da avaliação sobre formação colaborativa se faz, principalmente, a partir da análise das escolhas de adjetivos, advérbios e modalizadores. Assim, pode-se dizer que Isabela faz um movimento de se distanciar das representaçôes de Fernando, primeiramente, comprometendo-se de forma explícita, ainda que altamente modalizada, com a diferença ("eu acho que eu entendi a sua pergunta um pouco diferente") e, em seguida, introduzindo sentidos de divisão social do trabalho colaborativo. A escolha do termo hierarquia e sua posterior relexicalização por organização é importante para a compreensão desse distanciamento porque se contrapõe ao sentido de relaçóes equânimes de poder, presente na fala de Fernando ("todo mundo se ajudando em todas as escalas possíveis"). No entanto, mesmo reconhecendo relaçóes de poder no grupo ("pelo menos aqui assim existe de certa forma uma hierarquia...”), Isabela representa a hierarquia de modo distribuído entre a professora formadora de quem "parte muitas vezes a iniciativa" (e não sempre) e os demais envolvidos, que têm "essa participação direta".

As escolhas de Isabela (turno 20) por modalizações deônticas e epistêmicas baixas ("eu acho que"; "um pouco diferente"; "de certa forma"; "é como se ela fosse") podem indicar a distribuição de poder pelo próprio 
discurso. Se as relações de poder estão distribuídas pelas formas de participação, a emergência de relaçôes mais simétricas se liga à dialogicidade dos textos, marcada, dentre outros aspectos, pelo reconhecimento da diferença e pela linguagem da possibilidade e da suposição. Por outro lado, Isabela termina comprometendo-se fortemente com a verdade dos enunciados quando se refere ao papel daqueles, que não a professora formadora ("nós também temos essa participação direta"; "existe essa divisão"; "existe essa organização"). Neste processo de relexicalização de "hierarquia" com "divisão" com "organização", Isabela concede destaque à "participação direta" dos demais envolvidos como condição desejável do trabalho.

No entanto, a análise mostra que a metáfora do motor dilui as simetrias e revela ainda uma tensão entre opor-se a relações equânimes de poder e enunciar relações hierárquicas mitigadas por modalizadores. Por isso disse anteriormente que parece haver tanto a construção de sentidos de colaboração marcados pela simetria, quanto pela impossibilidade de "dizer" a hierarquia, seja pela dificuldade em reconhecê-la, seja por constrangimentos preexistentes na estrutura em que a prática se dá e que marcam a presença do indizível. Esses diferentes modos de compreender a formação colaborativa e as relaçóes de poder no interior do grupo vão ecoando ao longo do grupo focal.

\begin{tabular}{ll}
\hline (2) & \\
\hline 25 & $\begin{array}{l}\text { Tiago: Eu acho que assim como a Isabela disse... é uma hierarquia, mas } \\
\text { assim mesmo quando não tem uma hierarquia no grupo, sempre alguém se } \\
\text { sobressai das outras pessoas... daí a gente vê ele meio como o líder do } \\
\text { grupo, que direciona as ideias. }\end{array}$ \\
\hline 26 & $\begin{array}{l}\text { Carolina: Eu acho que tem que ter sempre alguém no comando... é } \\
\text { alguém que organiza, alguém que solte os comandos pra gente se organizar } \\
\text { e então realizar as tarefas que nos foi designada...” }\end{array}$ \\
\hline 27 & $\begin{array}{l}\text { Mariana: Eu acho o mesmo que já foi falado... eu só gostaria de complementar } \\
\text { que às vezes as ideias das coisas podem sair do aluno, só que a professora } \\
\text { formadora ela vai orientar a gente pra qual caminho seguir. }\end{array}$ \\
\hline
\end{tabular}

O termo hierarquia retorna no texto de Tiago, que reforça o sentido de relações de poder distribuídas pelas formas de participação dos envolvidos. $\mathrm{O}$ que se mostra relevante para a discussão que proponho são as metáforas que mapeiam as interpretações de colaboração em termos de liderança e de comando. Por um lado, a adesão de Tiago às representaçôes de Isabela reforçam o apagamento de hierarquia que decorre dos papéis institucionalizados. 
Embora ele coloque o "líder do grupo" como aquele que "direciona as ideias", sua representação de liderança se liga à natureza dos eventos e não às imposiçôes institucionais. Ao dizer "sempre alguém se sobressai das outras pessoas", Tiago se filia a uma visão de organização interna distribuída pelo reconhecimento no próprio grupo. O sujeito indefinido antes ("alguém se sobressai") é identificado como aquele que é colocado na posição de liderança pelos próprios membros do grupo ("a gente vê ele meio como líder do grupo"). Assim como para Isabela, é possível perceber aspectos da experiência da formação colaborativa em termos de relações (as)simétricas marcadas pelas formas de participação. Isso quer dizer que as possibilidades de agência e de protagonismo se ligam aos modos como os atores sociais são posicionados e posicionam-se nas práticas.

De outra forma, em adesão às representaçōes expressas por Fernando, Carolina e Mariana retomam, indiretamente, a metáfora de time 'comandado' por "alguém que organiza, alguém que solte os comandos". O sujeito indefinido para Carolina, marcado por modalização de obrigatoriedade ("tem que ter sempre alguém no comando"), ganha identidade na fala de Mariana: "a professora formadora". Em uma cultura fortemente marcada pela prática do futebol como parte essencial da identificação nacional, em que técnicos são chamados, pelos jogadores e dirigentes, de "professores", naturaliza-se a formação colaborativa comparada a um time composto por membros que mantém entre si relaçóes de poder fixas, pré-determinadas e estáveis. A contestação, tomada de iniciativa e de decisões não são valorizadas nos treinamentos deste esporte e aqueles que se colocam em oposição ao "professor" podem lidar com dificuldades no interior do grupo. Assim, a metáfora da formação colaborativa como time provoca um apagamento mais explícito do protagonismo dos/as licenciandos/as, uma vez que a eles/as cabe fazer aquilo 'que lhes foi designado', 'seguir o caminho que a professora formadora orientou'.

Ao dizer que é preciso "ter alguém que solte os comandos pra gente se organizar", Carolina estabelece uma relação de causação, cuja origem é depois identificada por Mariana como sendo a "a professora formadora" e os receptores são "a gente", indicando, possivelmente, serem os/as prórpios/as os/ as licenciandos/as. Com isso é possível supor que a hierarquia reaparece com outras roupagens, o que ajuda a sustentar a impossibilidade de enunciar, como indiquei anteriormente. Isso porque, como prática historicamente (re)produzida, existe uma hierarquia institucionalizada e consolidada, na qual situam-se professores/as e alunos/as com posições clássicas e bem delimitadas, ao mesmo tempo em que configura-se uma nova prática híbrida, com novas 
nebulosas posições que provocam tensões entre o que cada um/a faz, que responsabilidades têm. De um lado 'trocar ideias' é mais sedutor do que só cumprir comando. De outro, 'trocar figurinhas' é mais seguro do que assumir as responsabilidades pelas decisóes.

As práticas, portanto, preveem posições que são objetivas, mas ainda não subjetivamente preenchidas. No entanto, quando essas projeções vêm para o nível do realizado e recontextualizam-se nas práticas das IES e das escolas, as posições objetivas são preenchidas pelas subjetividades. Dai decorrem as possibilidades de criatividade, de inovação, de transformação. Assim como práticas híbridas, novas posições, por vezes também híbridas, ganham momentun e operam, sincronicamente, para novas possibilidades.

Carolina e Mariana comprometem-se fortemente com os enunciados, quase sempre colocados como fato, de modo generalizado e abstrato ("tem que ter sempre alguém no comando"; "a professora formadora ela vai orientar a gente pra qual caminho seguir”). Essas declarações contribuem para avaliação da formação colaborativa em termos daquilo que se deseja. A modalização de obrigatoriedade em "tem que ter sempre alguém no comando" implica que a hierarquia é desejável e que cabe ao/à professor/a da universidade assumir o "comando". Do mesmo modo, dizer que "ela vai orientar a gente para qual caminho seguir" pressupóe que haja um caminho, que o/a professor/a da universidade sabe qual é e que o define sozinho/a.

A significação de colaboração como 'troca de ideias' é presente no texto de Isabela que repete a metáfora outras três vezes e permite compreender aspectos desta experiência em termos de "partilha".

(3)

39 Isabela: [...] e é uma diferença muito grande... porque aqui existe uma partilha, basicamente não só com o professor... [...] e aqui a gente tem essa partilha com os alunos, a gente ta junto e com o professor, com o professor da escola que está em sala, [...] então essa partilha é muito diferente [...] essa partilha é o principal diferencial.

Do mesmo modo, a 'troca de figurinhas', embora não se repita literalmente ao longo do grupo focal, repercute nos sentidos da experiência em termos de "parceira" e de "complementaridade". 
(4)

58 Carolina: Eu acho que o bom disso é que as vezes o parceiro tem uma ideia melhor do que você, ou uma ideia que complementa... complementar essas ideias dos outros, faz um.. é... faz dar mais certo.

Para finalizar, as representações aqui enunciadas permitem ainda atribuir sentidos de formação colaborativa em termos de crescimento, de passagem da vida de criança - da qual trocar figurinhas e jogar em times fazem parte - para a vida adulta, quando se espera independência.

(5)

63 Tiago: Eu não tinha nenhuma experiência em dar aulas... então pra mim está sendo muito bom, está sendo uma aprendizagem muito legal... de assim, de entrar em sala de aula, de preparar a aula em si e ter sempre um plano B [...] Eu acho que isso daí está sendo muito importante para o meu crescimento mesmo.

$[\ldots]$

66 Elias: Você acredita que esse modelo [de formação colaborativa] pode contribuir pra sua prática? Sim ou não? Se sim, de que modo? Se não, por que não?

67 Tiago: Eu acho que sim e que não... porque ajuda a gente, dá um novo modo de ver as coisas, de pensar em atividades, de pensar em uma aula. Só que acaba criando uma dependência de um outro pra discutir e na hora que a gente entra de verdade em uma escola, muitas vezes a gente acaba não tendo esse outro pra... pra... pra se apoiar [...]

[...]

75 Isabela: [...] Mesmo que sejam 5 ou 10 alunos assim, ou $30 \ldots$ essa partilha de experiências assim: "a::: eu já fiz isso e não deu certo" eu acho que um ponto positivo assim... você aprende com os erros dos outros também [...] mas também existe essa ideia de que a gente um pouco que constrói uma dependência assim né... [...] sabendo fazer esse distanciamento de que essa é uma realidade o mercado de trabalho é uma outra realidade, é muito positivo.

[...]

80 Mariana: Então, eu acho que a troca de idéias é muito assim... significativa, mas a gente vai carregar isso com a gente, mas eu também acho que a gente vai na prática, você vai dar aula vai ser diferente... assim... você vai ter que se virar. Se você estiver com alguma coisa que não está dando certo, não vai ter ninguém pra te ajudar. Então, eu tenho que adaptar tudo isso pra realidade, né. 
Os trechos em itálico neste último exemplo criam-se a partir da metáfora do crescimento, introduzida por Tiago no turno 63, quando responde à pergunta: o que participar desse modelo de formação te possibilitou em termos de aprendizagem? Com base nela, vão-se construindo sentidos baseados na relação crescimento / independência / realidade.

A metáfora do crescimento é bastante utilizada na corrente desenvolvimentalista do pensamento educacional. Em linhas gerais, esta metáfora trata do desenvolvimento como decorrente dos processos maturacionais. Quanto mais idade têm as crianças, maiores as complexidades cognitivas com as quais conseguem lidar e mais ampliadas suas possibilidades de aprendizagem. Esta forma de representar os processos educacionais apresenta correlação àquelas que vivenciamos em nosso desenvolvimento biológico. O crescimento implica, portanto, na transição de uma fase da vida a outra e coloca aqueles que estão em crescimento, em nossa cultura, em posição de tornarem-se independentes.

Por esta razão, a metáfora do crescimento expóe o conflito entre o que se tem como desejável na formação colaborativa, conforme as expressões avaliativas ("ajuda a gente, dá um novo modo de ver as coisas, de pensar em atividades..."; "essa partilha de experiência [...] um ponto positivo assim... você aprende com o erro dos outros..."; "a troca de ideia é muito assim significativa") e o aquilo que contraria o próprio processo de crescimento porque "acaba criando uma dependência". A relação que se estabelece entre estes processos - o de crescer e, paradoxalmente, tornar-se dependente - permite representar a formação colaborativa como não-verdade ("na hora que a gente entra de verdade numa escola..."), como uma realidade distante da realidade do mercado de trabalho ("sabendo fazer esse distanciamento de que essa é uma realidade e o mercado de trabalho é uma outra realidade") e também como não-realidade ("eu tenho que adaptar tudo isso pra realidade"). A escolha por esta metáfora do 'crescimento' recria os sentidos das cenas duplas, como discutimos na metáfora do 'reflexo' (exemplo 1), não como elementos que se articulam, mas como realidades distintas.

Isso remete também e, finalmente, às posições tensas e incertas que ocupam os/as licenciandos/as nessa nova prática social. Mariana, ao dizer no turno 80 "você vai dar aula vai ser diferente", enuncia o lugar de não-professora que ocupou durante o Pibid, cuja experiência também só será uma realidade quando essa posição for plenamente preenchida. Talvez, por isso, haja em seu texto marcas de dificuldade de enunciação, sinalizadas no uso de modalidade 
epistêmica baixa ("eu acho que a troca de ideia é muito assim... significativa”), na repetição de adversativas ("mas a gente vai carregar isso com a gente, mas eu também acho..."), na hesitação ("você vai dar aula vai ser diferente... assim... você vai ter que se virar"). Parece razoável supor que as tensões que discutimos sejam próprias dessa nova prática que, mesmo incerta e não consolidada, oferece a oportunidade de ocupar diferentes posiçôes ao mesmo tempo tornando-se, por isso, celebrada quando comparada ao rompimento umbilical de quem sai da universidade como aluno/a para ser professor/a no dia seguinte.

\section{Considerações finais}

Este trabalho foi motivado pelo interesse em compreender que representações fizeram os/as licenciandos/as envolvidos/as no Pibid das práticas de formação colaborativa que vivenciaram em 2011. Sabemos que essa representações se ligam às atitudes, experiências sociais e ideologias prévias de cada um/a, compartilhadas com outros membros do grupo no processo de vivenciar a historicidade da ação. Isso quer dizer que, mesmo que se possa discutir colaboração numa perspectiva normativa, definindo-a e caracterizando-a previamente, a formação colaborativa é uma realização discursiva operacionalizada pelas dinâmicas das relações sociais vividas pelos/as participantes da prática social específica. Assim, esses ainda são passos iniciais que buscam compreender menos o que é colaboração e mais os modos como as pessoas representam experiências vivenciadas em grupos que se propõem colaborativos.

O que a análise permite discutir é que, embora os participantes tivessem se apropriado de expressões semelhantes na trama interdiscursiva, aproximaramse na aparência dos sentidos, mas distanciaram-se na essência. Tanto Fernando quanto Isabela usam as metáforas associadas à 'troca' e à 'máquina', mas o fazem para expressar diferentes contornos da formação colaborativa. Ao redor da metáfora de 'troca de ideias', trazida por Isabela, circularam como desejáveis: articulação das experiências de formação colaborativa com o mundo da vida; apagamento das hierarquias institucionalizadas e relações de poder distribuídas por meio da participação direta dos envolvidos; liderança que decorre do reconhecimento do grupo; organização flexível do trabalho. De outra forma, a metáfora da 'troca de figurinhas', introduzida por Fernando, revelou que, na formação colaborativa, são desejáveis: relações de poder definidas pelos lugares institucionais dos atores sociais; contribuiçôes individuais para formação do todo; complementariedade; comando. 
Os textos analisados apresentaram ainda alta densidade avaliativa por meio da qual os/as licenciandos/as comprometeram-se com valores desejáveis na formação colaborativa, tais como: compartilhar experiências, planejar conjuntamente, aprender pela experiência do outro. Ao mesmo tempo, foram enunciados como indesejáveis, principalmente, a dependência que a formação colaborativa promove e o fato desta ser uma prática temporária e situada no contexto da universidade.

As discussões aqui feitas permitem vislumbrar tenso-es discursivas associadas ao sistema posiçãao-prática instanciado nos eventos sociais específicos, vivenciados por esses licenciandos/as com quem conversamos.

Por um lado, tanto no Decreto quanto no subprojeto há marcas que projetam para esses/as licenciandos/as uma 'atuação como' professores/as, seja enunciando sua inserção no cotidiano de escolas, seja reposicionando-os como novos profissionais. Por outro, as análises indicam a não ocupação plena desses lugares. Parece razoável supor que as causas desses conflitos decorram das posiçōes híbridas que os/as licenciandos ocupam em práticas de formação docente, uma vez que tanto são alunos/as, no contexto das IES, quanto 'vistos como' professores/as, no contexto das escolas. Assim, sua participação no Pibid, ainda que se deseje colaborativo, está condicionada às relaçôes hierarquicamente consolidadas.

Isso traz algumas implicaçôes importantes.

Considerando que as estruturas são sempre prévias às açōes e que, nesse sentido, agência é sempre uma potencialidade (e não um atributo individual preexistente), torna-se necessário assumir o compromisso de organziar espaços para participação plena daqueles/as envolvidos nas práticas no interior do Pibid. Isso envolve definir mais claramente, de forma democrática e dialógica, expectativas, modos de atuação, possibilidades de contribuição. Não parece ser suficiente acomodar os subprojetos do Pibid na organização curricular vigente nas IES ou tê-los em relação de concomitância aos chamados "estágios".

Práticas híbridas não são somatórias de diferentes práticas, mas novas possibilidades criadas no encontro e confronto daquilo que já se conhece. Assim, mesmo que haja na essência das normativas do Pibid pressupostos de uma prática colaborativa para formação de professores/as, para que isso se realize serão necessários novos padrões de gerenciamento coletivo das responsabilidades relacionadas às práticas de ensino-aprendizagem, em que a pluralidade seja tomada como princípio de organização dos processos.

Por fim, parece razoável supor que práticas de natureza colaborativa, para se tornarem "reais", precisam incorporar de modo claro e legítimo as diferentes 
formas de conhecimento profissional. Não se trata, portanto, de imaginar, como se lê no Decreto, que a inserção de licenciandos/as no cotidiano das escolas seja suficiente. Tampouco que a mobilização de professores como co-formadores seja o bastante. Modelos em que a formação de professores/as prescindem das IES operam a favor de uma abordagem técnico-racionalista (FURLONG et al., 2000). As complexidades envolvidas na tarefa de ensinar-aprender ganham potencial criativo na medida em que valorizam aquilo que cada participante e instituição trazem de essencialmente diferente para o desenvolvimento do todo.

Agradecimentos:

Este trabalho foi possível graças ao apoio do Departamento de Letras Estrangeiras Modernas, da Universidade Estadual de Londrina, pela licença, da Fundação Araucária, pela concessão de bolsa, e do Programa de Pós-Graduação em Linguística, da Universidade de Brasília, pelo acolhimento do projeto de pós-doutoramento. Agradeço ao bolsista de Iniciação Científica, Elias de Oliveira Fernandes Junior, pelos dados gerados por meio do questionário e junto ao grupo focal, a Adriana Grade Fiori e a Viviane de Melo Resende, pelas leituras, apontamentos e ensinamentos.

\section{Referências}

BHASKAR, R. Societies. In: ACHER, M. et al. (Org.). Critical Realism. Essential Readings. London; New York: Routledge, 1998. p. 206-257.

CHOULIARAKI, L.; FAIRCLOUGH, N. Discourse in Late Modernity: Rethinking Critical Discourse Analysis. Edinburgh: Edinburgh University Press, 1999.

CLARK, C. et al. Collaboration as Dialogue: Teachers and Researchers Engaged in Conversation and Professional Development. American Educational Research Journal, v. 3, n. 1, p. 193-231, 1996.

ENGESTRÖM, Y. Teachers as Collaborative Thinkers: Activity-Theoretical Study of an Innovative Teacher Team. In: CARLGREN, I. et al. (Ed.). Teachers' Minds and Actions: Research on Teachers' Thinking and Practice. Falmer, 1994. p. 43-61.

FAIRCLOUGH, N. Analysing Discourse: Textual Analysis for Social Research. London: Routledge, 2003.

FAIRCLOUGH, N. Semiotic Aspects of Social Transformation and Learning. In: ROGERS, R. (Ed.). An Introduction to Critical Discourse Analysis. 2. ed. New York; London: Routledge, 2011. p. 119-127. 
FURLONG, J. et al. Teacher Education in Transition: Re-Forming Teaching Professionalism. Buckingham: Open University Press, 2000.

GAFFURI, P. Rupturas e continuidades na formação de professores: um olhar para as práticas desenvolvidas por um grupo no contexto do PIBID-Inglês/UEL. 2012. 141 f. Dissertação (Mestrado em Estudos da Linguagem) - Universidade Estadual de Londrina, Londrina, 2012.

JOHN-STEINER, V. Creative Collaboration. New York: Open University Press, 2000.

JOHN-STEINER, V.; WEBER, R. J.; MINNIS, M. The Challenge of Studying Collaboration. American Educational Research Journal, v. 35, p. 773-783, 1998. KRZYZANOWSKI, M. Analysing Focus-Groups. In: WODAK, R.; KRZYZANOWSKI, M. (Ed.). Qualitative Discourse Analysis in the Social Sciences. Basingstoke: Palgrave, 2008. p. 162-181.

LAVE, J. Cognition in Practice: Mind, Mathematics, and Culture in Everyday Life. Cambridge (UK): Cambridge University Press, 1988.

LAVE, J.; WENGER, E. Situated Learning: Legitimate Peripheral Participation. Cambridge (UK): Cambridge University Press, 1991.

LIBERALI, F; MAGALHÂES, M. C. C. Formação de professores e pesquisadores: Argumentando e compartilhando significados. In: TELLES, J. A. (Org.). Formação inicial e continuada de professores de línguas: dimensões e ações na pesquisa e na prática. Campinas: Pontes, 2009. p. 43-66.

LOPES, R. S. B. A narrativa litera'ria: um jogo de espelhos. O Eixo e a Roda, Belo Horizonte, v. 21, n. 1, p. 109-115, 2012.

MAGALHÃES, M. C. C. O método para Vygotsky: a zona proximal de desenvolvimento como zona de colaboração e criticidade criativas. In: SCHETTINI, R. H. et al. (Org.). Vygotsky: uma (re)visita no início do século XXI. São Paulo: Andross, 2009a. p. 53-78.

MAGALHÃES, M. C. C. Pesquisa crítica de colaboração em projetos de formação contínua em contextos escolares: colaboração na pesquisa e na ação. In: BALDI, E. M. B.; FERREIRA, M. S.; PAIVA, M. (Org.). Epistemologia das Ciências da Educação. Natal: Editora da UFRN, 2009b. p. 227-243.

MAGALHÂES, M. C. C.; FIDALGO, S. Critical Collaborative Research: Focus on the Meaning of Collaboration and on Mediational Tools. Revista Brasileira de Linguistica Aplicada, Belo Horizonte, v. 10, n. 3, p. 773-797, 2010.

MAGALHÃES, M. C. C.; FIDALGO, S. Teacher Education Language in Collaborative and Critical Reflective Contexts. In: GIL, G.; VIEIRAABRAHÃO, M. H. (Org.). Educação de professores de línguas: os desafios do formador. Campinas: Pontes, 2008. p. 105-126. 
MATEUS, E. Aprendizagem sem fronteiras: ressignificando os limites da formação inicial e contínua de professores. In: ABRAHÃO, M. H.; GIL, G.; RAUBER, A. C. (Org.). Anais do I Congresso Latino-Americano sobre Formação de Professores de Linguas. Florianópolis: UFSC, 2007. p. 672-689. Disponível em: <http:// www.cce.ufsc.br/ clafpl/pagina_principal1.htm>. Acesso em: out. 2007.

MATEUS, E. Atividade de aprendizagem colaborativa e inovadora de professores: ressignificando as fronteiras dos mundos universidade-escola. 2005. 327 p. Tese (Doutorado em Linguística Aplicada e Estudos da Linguagem) - Pontifícia Universidade Católica de São Paulo, São Paulo, 2005.

MATEUS, E. Práxis colaborativa e as possibilidades de ser-com-o-outro. In: SCHETTINI, R. H. et al. (Org.). Vygotsky: uma (re)visita no início do século XXI. São Paulo: Andross, 2009. p. 17-52.

MATEUS, E. Um esboço crítico sobre parceria na formação de professores/as. Revista Brasileira de Educação; Educação em Revista, no prelo.

MATEUS, E.; QUEVEDO-CAMARGO, G.; GIMENEZ, T. (Org.). Ressignificações do NAP: rupturas e continuidades. Londrina: EDUEL, 2009.

MATUSOV, E.; HAYES, R. Building a Community of Educators versus Effecting Conceptual Change in Individual Students: Multicultural Education for Pre-Service Teachers. In: WELLS, G.; CLAXTON, G. (Ed.). Learning for Life in the $21^{s t}$ Century: Sociocultural Perspectives on the Future of Education. London: Blackwell, 2002. p. 239-251.

MATUSOV, E.; WHITE, C. Defining the Concept of Open Collaboration from a Sociocultural Framework. Cognitive Studies: The Bulletin of the Japanese Cognitive Science Society, v. 3, n. 4, p. 10-13, 1996.

PICONI, L.; MATEUS, E. Ressignificações de identidades de professores: uma análise do encontro com o outro. In: REIS, S.; VAN VEEN, K.; GIMENEZ, T. Identidades de professores de linguas. Londrina: EDUEL, 2011. p. 291-315.

RESENDE, V. de M. Análise discursiva crítica do uso de metáforas em uma interação etnográfica no movimento nacional de meninos e meninas de rua. Revista da Abralin, Belém, v. 8, n. 1, p. 125-148, jan.-jun. 2009.

ROGOFF, B. Observing Sociocultural Activity on Three Planes: Participatory Appropriation, Guided Participation, and Apprenticeship. In: WERTSCH, J.; DEL RIO, P.; ALVAREZ, E. (Ed.). Sociocultural Studies of the Mind. Cambridge (UK): Cambridge University Press, 1995. p. 139-164.

ROGOFF, B.; TURKANIS, C. G.; BARTLETT, L. (Ed.). Learning Together: Children and Adults in a School Community. Oxford (UK): Oxford University Press, 2001. 
ROTH, W. M.; TOBIN, K. Coteaching: From Praxis to Theory. Teachers and Teaching: Theory and Practice, v. 10, n. 2, p. 161-180, Apr. 2004.

ROTH, W. M.; TOBIN, K. Redesigning an "Urban" Teacher Education Program: An Activity Theory Perspective. Mind, Culture and Activity, v. 9, n. 2, p. 108-131, 2002.

ROTH, W. M.; TOBIN, K. The Implications of Coteaching/Cogenerative Dialogue for Teacher Evaluation: Learning from Multiple Perspectives of Everyday Practice. Journal of Personnel Evaluation in Education, v. 15, n. 1, p. 7 29, 2001.

SAYER, A. Realism and Social Science. London: Sage, 2000.

VAN DIJK, T. A. Discurso e poder. 2. ed. São Paulo: Contexto, 2010.

WENGER, E. Communities of Practice: Language, Meanings and Practice. Cambridge (UK): Cambridge University Press, 1998.

Recebido em 08/01/2013. Aprovado em 02/08/2013. 